\title{
Simulating forensic casework scenarios in experimental studies: The generation of footwear marks in blood
}

Rachel L. McElhone $e^{\mathrm{a}, \mathrm{b}}$, rachel.I.mcelhone@bath.edu

Georgina E. Meakin a,b, g.meakin@ucl.ac.uk

James C. French ${ }^{a, b}$, james.french@ucl.ac.uk

Tracy Alexanderc, $\underline{\text { Tracy.Alexander@city-of-Iondon.pnn.police.uk }}$

Ruth M. Morgana, ${ }^{a, b}$ ruth.morgan@ucl.ac.uk

a UCL Centre for the Forensic Sciences, 35 Tavistock Square, London, WC1H 9EZ, UK

b UCL Department of Security and Crime Science, 35 Tavistock Square, London, WC1H 9EZ, UK

c Forensic Services, City of London Police, 37 Wood Street, London, EC2P 2NQ, UK

\section{Key words}

Forensic science; footwear marks; blood; empirical data; interpretation; trace evidence

\section{Abstract}

A study was designed to investigate the effects of external variables, including blood type, flooring surface, footwear tread depth and blood dryness, on the appearance of blood-based footwear marks, with particular reference to simulating a specific casework scenario. Results showed that footwear marks left in human blood tended to be of greater quality than those in equine blood, highlighting a potential issue in applying data generated with equine blood to human bloodstains in casework. Footwear tread effects were also dependent on blood type, but the type of flooring surface did not affect the appearance of the mark. Under some conditions, as the blood dried, the amount of detail retained from footwear contact decreased. These 
results provide the beginnings of an empirical evidence base to allow a more accurate interpretation of blood-based footwear marks in forensic casework. When applied to a disputed bloodstain in a specific case, these results also demonstrate the importance of such experiments in narrowing the range of explanations possible in the interpretation of forensic evidence.

\section{Introduction}

In recent years, there has been debate concerning the value of experimental studies to inform forensic evidence interpretation, particularly regarding the issues of practitioner experience versus empirical research [1, 2]. Without empirical research on which to base our understanding of the meaning and significance of different forms of evidence, the value forensic evidence provides to a criminal investigation is arguably limited. Footwear mark evidence requires such an empirical foundation for interpretation [3], and whilst progress has been made [4], further research is still required. Of particular importance is the generation of data to inform the interpretation of bloodstains that have been altered through contact with objects, such as items of footwear. Consideration of factors, such as the dryness of blood and the orientation of the surface on which the blood is deposited, that affect the appearance and quality of blood-based fingermarks is required for their interpretation [5], suggesting that similar considerations are required for the interpretation of blood-based footwear marks.

This study therefore examined external factors, including blood type, flooring surface, footwear tread depth, and the degree to which blood has dried, that might affect the formation of blood-based footwear marks and therefore their interpretation in casework. These factors were investigated within the context of an experiment aimed at simulating a specific casework scenario to assist in ruling out explanations of the origin of a contentious bloodstain. That case is the murder of Inge Lotz in South Africa in 2005, who was found in her home with blunt-force injuries to the head and multiple stab wounds to the neck and chest. An isolated bloodstain found on the floor of the 
bathroom (Fig. 1) was disputed at trial. The prosecution hypothesised that the stain had been made when the right sports trainer of the offender had made contact with two blood droplets, which had been passively deposited on to the tile floor during an attempt to clean the murder weapons in the bathroom sink. The defence, however, hypothesised that the bloodstain was a transfer mark from a bloodied weapon, made by the weapon being placed on the bathroom floor during the clean-up attempt, and therefore there was no relationship between the footwear tread of the defendant and the bloodstain.

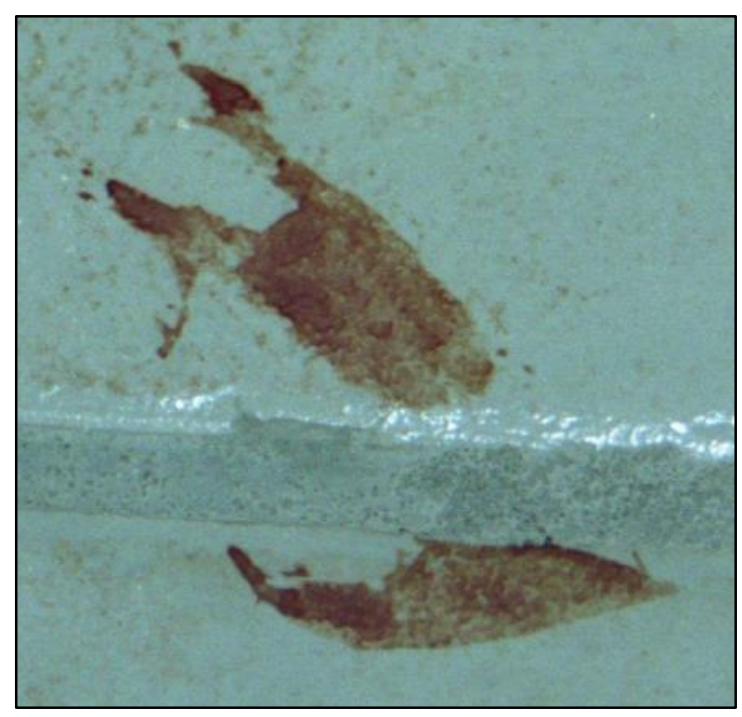

Fig. 1. Disputed bloodstain found on the tiled bathroom floor in the Inge Lotz case.

\section{Materials and Methods}

\subsection{Materials and samples used}

\subsubsection{Blood samples}

Given that the use of human blood in experiments is often not possible, due to issues of availability and the potential of health risks from blood-borne diseases, researchers commonly employ a human blood proxy such as equine blood [6]. Whilst similarities between equine and human blood have been observed [7], the sufficiency of this proxy in casework simulation experiments to assist forensic evidence interpretation has not 
been established empirically. As such, we conducted experiments with both human and equine blood to explore the validity of using equine blood as a human substitute for studying blood-based footwear marks.

For experiments with equine blood, $100 \mathrm{ml}$ of defibrinated equine blood was obtained from TCS Biosciences Ltd and stored at $4-8^{\circ} \mathrm{C}$ at all times. For experiments with human blood, $25 \mathrm{ml}$ of blood was drawn from the experimenter and stored in sterile evacuated tubes containing EDTA at room temperature, in accordance with recommended storage instructions. Whilst preventing coagulation, EDTA has minimal effect on the structure of blood cells within 5 hours of amalgamation, and as such the blood remains representative of untreated human blood for this period [8, 9]. Therefore, all trials with human blood were completed within 5 hours from the blood drawing, and once completed, all the blood samples were immediately destroyed.

\subsubsection{Depths of footwear tread}

All footwear used in these studies had previously been worn to be representative of the nature of items of footwear in forensic casework. Three depths of tread from the right-side of the footwear pair were used (Fig. 2): 'no tread', a male suit shoe (Office) of size 7 that had been worn weekly for work for a period of four months; 'shallow tread', a male suit shoe (ASOS) of size 9 that had been worn twice a month for a period of one year; and 'deep tread', a male sports trainer (Adidas, 'Supernova') of size 9 that had been worn twice a week for sporting activity over a period of one year. Such a deep tread trainer was specifically used to represent the footwear, a 'Squash Crown' Hi-Tec trainer, belonging to the defendant in the Inge Lotz case. 

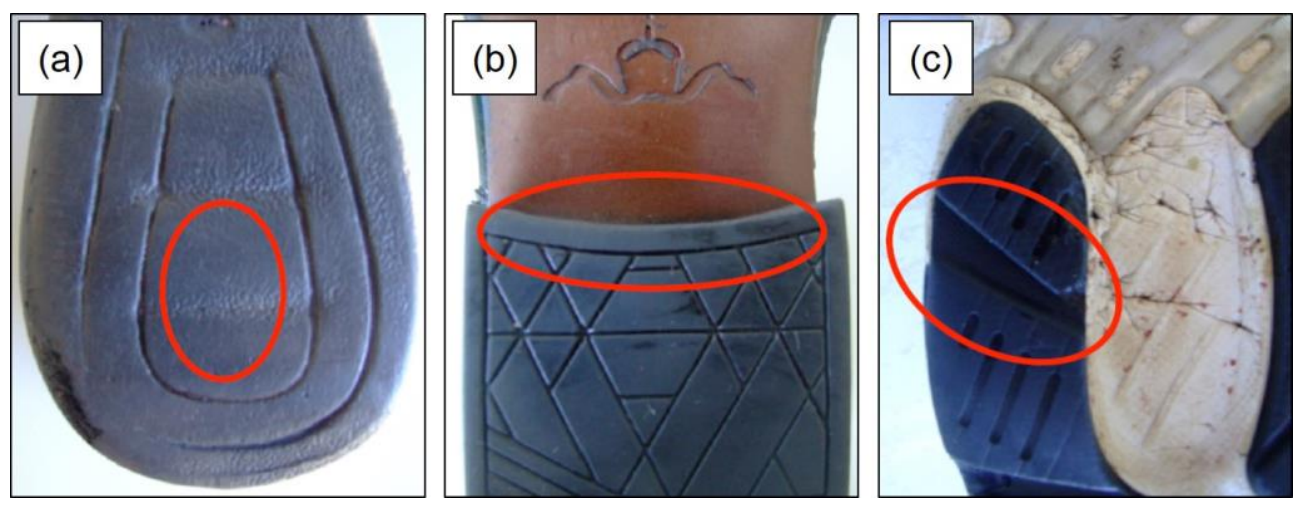

Fig. 2. Depths of footwear treads used to produce the footwear marks in blood: (a) 'no tread'; (b) 'shallow tread'; (c) 'deep tread'. Red ovals indicate the area of contact between the footwear tread and the blood droplet.

\subsubsection{Types of flooring}

Two types of flooring surface were considered, a ceramic tile ( $8 \mathrm{~mm}$ deep) (Porcelanosa), representative of the type of flooring in a bathroom, and a section of varnished oak wood flooring (15 mm deep) (Kahrs), representative of the types of flooring commonly found in residential buildings. A layer of cardboard was added to the bottom of the tile to increase its thickness to $15 \mathrm{~mm}$, to ensure that both flooring types were of the same depth.

\subsection{Experimental design}

The formation of blood-based footwear marks was investigated using a specially designed apparatus (see Section 2.3 and Fig. 3) to place items of footwear on to a drop of blood previously placed on a section of flooring that ensured consistency of the placement of the footwear and the pressure of the contact. A single droplet of blood was passively released from a $3 \mathrm{ml}$ plastic pastette, positioned $65 \mathrm{~cm}$ (the average distance blood falls from a hand held weapon [10]) directly above a piece of flooring. On both types of flooring, the blood droplet formed a circle on the surface as it landed (Fig. 3); blood droplets that did not have a circular formation were discarded. To further ensure consistency in the blood droplet, the diameters of ten droplets of blood for each blood type on each type of surface were measured. The average 
diameter of a blood droplet landing on wood was $16.3 \pm 0.7 \mathrm{~mm}$ and $16.7 \pm 0.5 \mathrm{~mm}$ for equine and human blood, respectively. On the tile surface, the average diameters were $17.7 \pm 0.7 \mathrm{~mm}$ and $18.3 \pm 0.8 \mathrm{~mm}$ for equine and human blood, respectively. A Mann-Whitney $U$ test showed that there were no significant differences in diameter between equine and human blood droplets on wood $(U=33.5, p=0.156)$ or on tile $(\mathrm{U}=29.0, p=0.091)$.

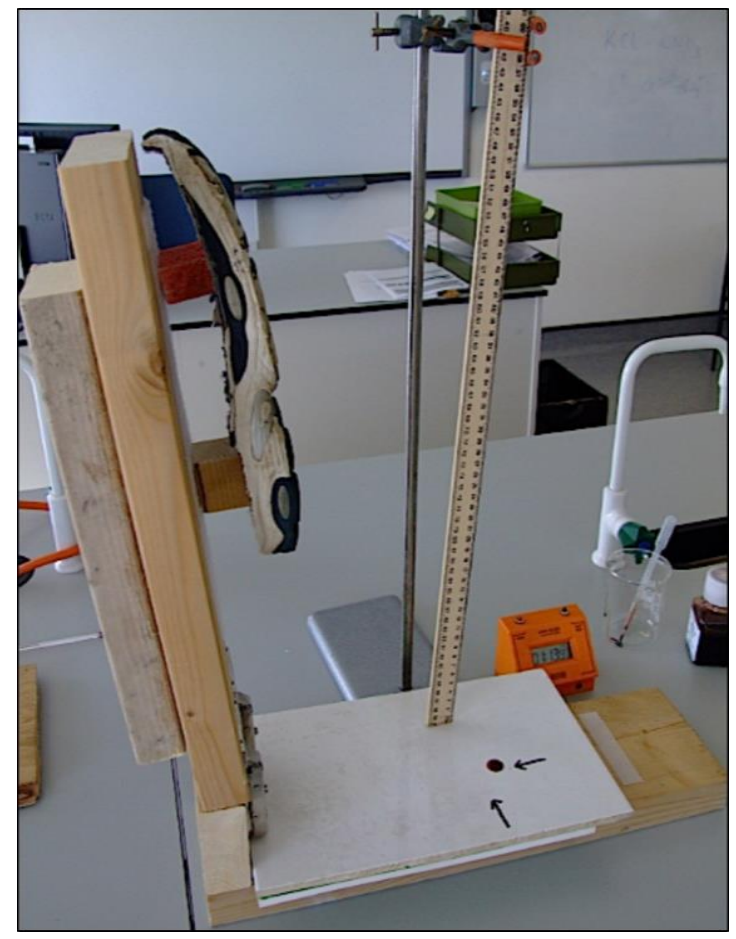

Fig. 3. Apparatus constructed to place footwear on to each blood spot to maintain a consistent force and angle of contact between trials; arrows depict the position of each blood spot.

Once the blood droplet had landed (or after a set time interval, as described below), the experimental footwear sole was lined up to allow contact of the blood within a preestablished region of the heel of the tread (Fig. 2); the heel being the purported point of contact in the Inge Lotz case. The mechanism of the apparatus was then allowed to naturally fall shut from a height of $20 \mathrm{~cm}$ above the flooring. The footwear sole landed on the flooring surface with an average force of $16.4 \mathrm{~N}$, a smaller force than that of $3,500 \mathrm{~N}$ for an average footstep [11], to attempt to replicate the placing of 
footwear by hand on to the floor. The mechanism was opened immediately after it closed to reduce the opportunity for the footwear sole to bounce. The resulting blood pattern was photographed with a centimetre scale using a digital camera (Fujifilm FinePix S9600). All photographs were taken directly above the footwear mark from a height of $13 \mathrm{~cm}$. After each experiment, both the footwear tread and section of flooring were cleaned with a sterile wipe and dried thoroughly to remove the possibility of contaminating trials with previously-transferred blood.

Experiments using this design were repeated with all combinations of the different types of blood (equine or human), footwear tread depth (no tread, shallow, or deep), and flooring surface (wood or tile). Additionally, the quality of the footwear marks obtained was investigated over various time points between blood deposition and contact with the footwear. For equine blood, the time intervals from release of the blood droplet and contact with the footwear tread were: 0, 3, 6, 9, 12, 15, 18, 21, and 24 minutes. Each time interval was repeated three times with each footwear tread depth and on both the tile and wood surfaces, totalling 162 samples. Due to the limited availability of human blood, fewer time intervals (3, 9, and 15 minutes) were recorded for this type of blood. Again, each time interval was repeated in triplicate with each depth of footwear tread and on both types of flooring, totalling 54 samples. These time intervals gave the blood drop opportunity to dry and congeal, allowing any effect this might have on the resultant footwear marks to be investigated.

\subsection{Construction of footwear-placing apparatus}

Apparatus was constructed to ensure the delivery of a consistent force and angle of contact between the different items of footwear and the blood drop, in a similar manner to the mechanism utilised by Farrugia et al 2012 [11]. The apparatus used in this research is depicted in Fig. 3. Slow shutting hinges were used to give resistance when closing the mechanism and to prevent the sole from bouncing when contacting the chosen surface. Velcro was used to ensure the flooring was immovable during each trial, whilst enabling changes of flooring surface and footwear sole for experimental 
variation. Each footwear sole was removed from the upper footwear structure and fitted to a wooden frame, to enable consistent contact with the flooring surface and comparable angles of contact when shutting the mechanism.

\subsection{Grading of the footwear marks and statistical analysis}

The quality of blood-based footwear marks is defined here as the amount of detail that the mark retained from the footwear sole that made that mark. To reduce subjectivity in recording the quality of the marks, a numerical grading system was employed that permitted the quantification of the detail exhibited by the marks (Table 1). Each mark was graded from its photograph in a random order to reduce the opportunity for examiner bias. This process was repeated three times to ensure consistency in the grading of each footwear mark. The resulting data sets were subjected to appropriate statistical analyses using the IBM SPSS Statistics 22 programme.

Table 1. Numerical system used to grade the quality of the blood-based footwear marks generated.

\begin{tabular}{cl}
\hline Grade & Description \\
\hline 0 & No disturbance of blood droplet \\
1 & $\begin{array}{l}\text { Some disturbance of blood droplet; droplet becomes less circular and more } \\
\text { irregular in shape }\end{array}$ \\
2 & Some disturbance of blood droplet; corresponds to contact with footwear tread \\
3 & Blood droplet disturbed with distinctive footwear mark \\
4 & Blood droplet disturbed with distinctive footwear mark and pattern of tread \\
\hline
\end{tabular}




\section{Results}

\subsection{Effect of blood drying time on quality of footwear marks}

Given that blood will start to dry after its deposition, it was hypothesised that with increasing time between blood deposition and footwear contact, the disturbance of the blood by contact with the footwear would decrease, thereby reducing the quality of the resultant footwear marks. The average qualities of blood-based footwear marks on tile and wood flooring, at various time points between blood deposition and contact with footwear of different treads, are shown in Fig. 4 for equine blood and Fig. 5 (a, b, c) for human blood. A Spearman's rank correlation was used to explore whether such a relationship between mark quality and blood drying time was observed with the marks made by the three tread types (no, shallow, and deep tread) on the two different floor surfaces for the two types of blood (Table 2).

For both equine and human blood on tile flooring, a statistically significant strong negative correlation was found between the blood drying time and the quality of the marks resulting from footwear with a shallow tread (Table 2). Statistically significant strong negative correlations were also found for deep tread marks in equine blood on wood, and for no tread marks in human blood on wood and tile (Table 2). These results indicate that for these combinations of blood, flooring, and footwear tread types, as the blood dried, the quality of the resultant footwear marks decreased. However, no such statistically significant correlations were observed for the other combinations of tread and flooring types for marks made in both blood types (Table 2). 

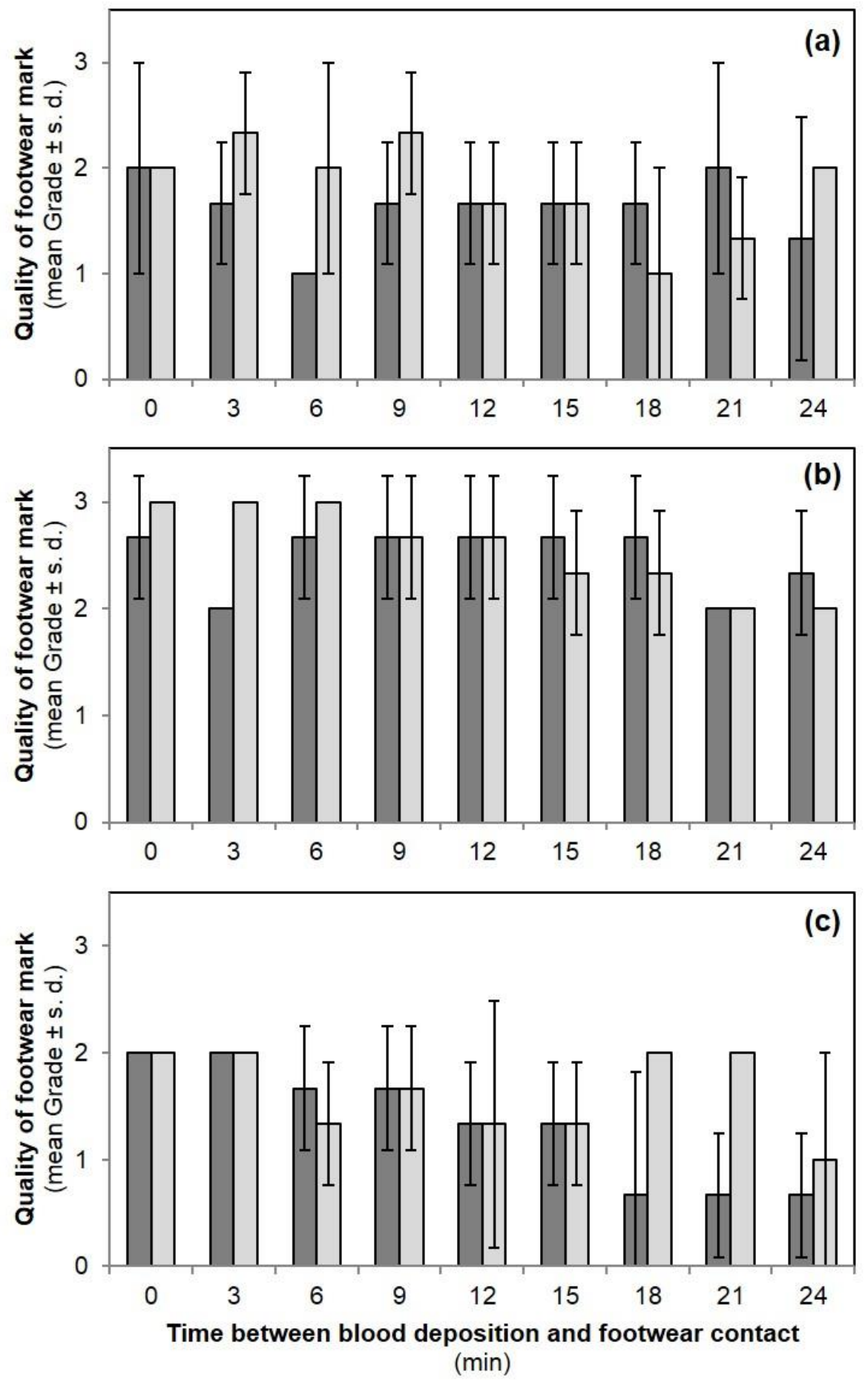

Fig. 4. Average quality of footwear marks made in equine blood with increasing time between blood deposition and footwear contact. Marks were made by footwear with 'no tread' (a), 'shallow tread' (b), and 'deep tread' (c) on wood (dark grey bars) and tile (light grey bars) flooring. Data are presented as mean Grade \pm standard deviation (s. d.) of three replicates; no error bars are shown when all three replicates for the same trial were assigned the same Grade. The x-axes on panels (a) and (b) are the same as that shown on panel (c). 

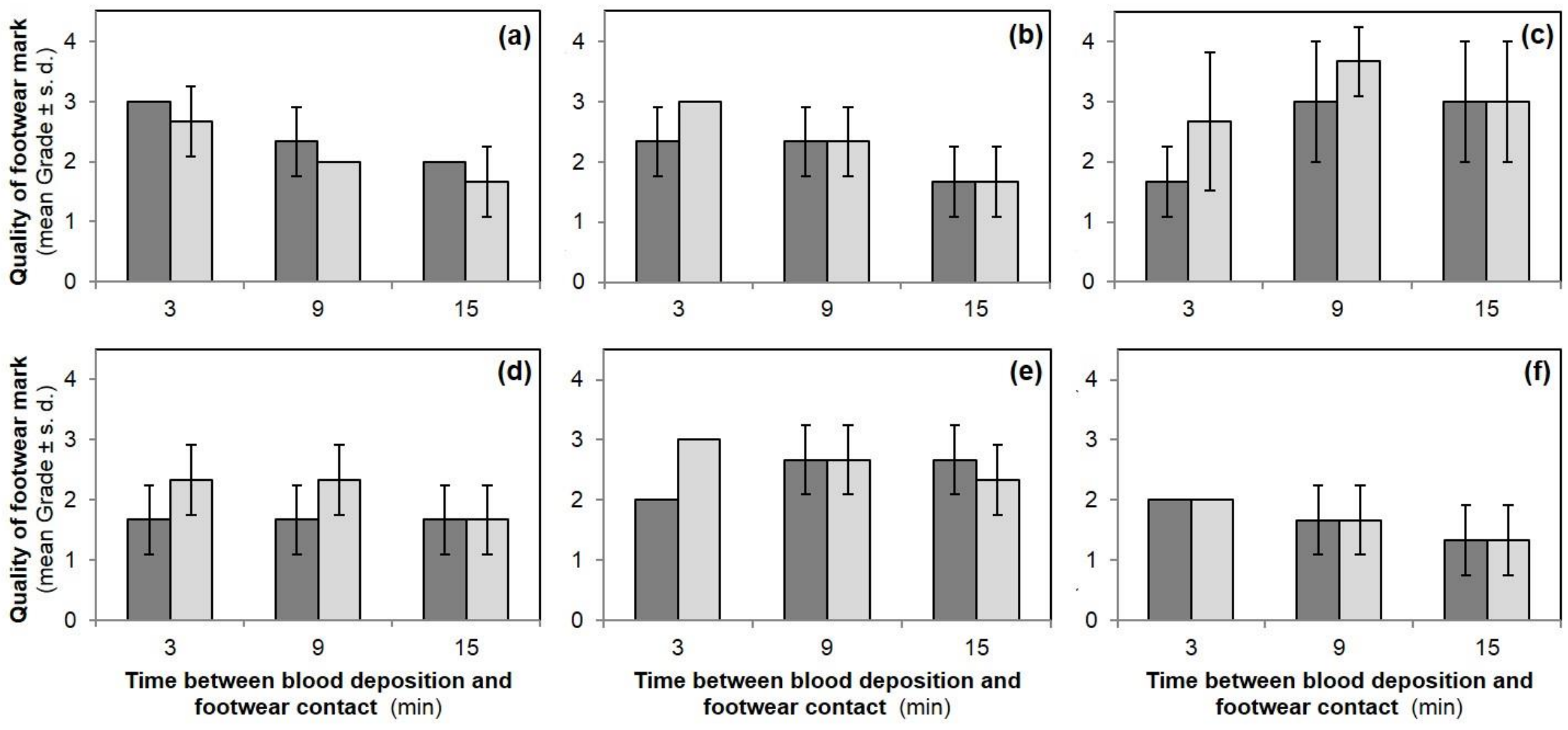

Fig. 5. Average quality of footwear marks made in human (a), (b) and (c) and equine (d), (e) and (f) blood at the same time points between blood deposition and footwear contact. Marks were made by footwear with 'no tread' (a) and (d), 'shallow tread' (b) and (e), and 'deep tread' (c) and (f) on wood (dark grey bars) and tile (light grey bars) flooring. Data are presented as mean Grade \pm standard deviation (s. d.) of three replicates; no error bars are shown when all three replicates for the same trial were assigned the same Grade. The y-axes on panels (b), (c), (e) and (f) are the same as those shown on panels (a) and (d), and the x-axes on panels (a), (b) and (c) are the same as those shown on panels (d), (e) and (f). 
Table 2. Correlations between blood drying time and footwear mark quality for the various combinations of different types of blood, flooring and footwear tread depth. The Spearman's rank correlation coefficient (rho) and its corresponding $p$ value are presented for each combination.

\begin{tabular}{ccccc}
\cline { 2 - 5 } & \multicolumn{2}{c}{$\begin{array}{c}\text { Equine blood } \\
\text { [rho }(\boldsymbol{p})]\end{array}$} & \multicolumn{2}{c}{$\begin{array}{c}\text { Human blood } \\
\text { [rho }(\boldsymbol{p})]\end{array}$} \\
\hline $\begin{array}{c}\text { Footwear } \\
\text { tread }\end{array}$ & Wood & Tile & Wood & Tile \\
\hline \multirow{2}{*}{ No tread } & 0.037 & -0.365 & $-0.822^{* *}$ & $-0.724^{*}$ \\
& $(0.855)$ & $(0.061)$ & $(0.007)$ & $(0.027)$ \\
Shallow & -0.115 & $-0.751^{* *}$ & -0.472 & $-0.837^{* *}$ \\
& $(0.568)$ & $(0.000)$ & $(0.199)$ & $(0.005)$ \\
Deep & $-0.711^{* *}$ & -0.181 & 0.583 & 0.141 \\
& $(0.000)$ & $(0.367)$ & $(0.099)$ & $(0.718)$ \\
\hline \multicolumn{2}{r}{${ }^{*}$ Significance at the 0.05 level; ** Significance at the 0.01 level }
\end{tabular}

\subsection{Effect of flooring type on quality of footwear marks}

In designing the experimental set-up of this research, a preliminary experiment to examine the size of blood droplets used in this study was conducted (see Section 2.2). In doing so, it was observed that the droplets of blood formed larger circles on the tile flooring than on the wooden flooring. A Mann-Whitney $U$ test showed that the diameters of the blood drops were statistically significantly larger on tile than on wood for both equine $(U=8.00, p=0.001)$ and human $(U=7.00, p=0.001)$ blood. It was therefore proposed that footwear marks left in blood on a tiled floor might be of greater quality than those left on a wooden floor. All the time points (shown in Fig. 4 for equine blood and Fig. 5 ( $a, b, c)$ for human blood) were grouped together as individual populations of data for each tread type in each type of blood on each flooring surface. Potential effects of flooring type on footwear mark quality were examined by comparing the different data sets for each footwear tread depth using a Mann-Whitney $U$ test. For both equine and human blood, no significant differences were detected between the qualities of footwear marks on wood and of those on tile (Table 3). 
Table 3. Comparisons between flooring type and footwear mark quality for the different footwear treads in equine and human blood. The Mann-Whitney $U$ statistic $(U)$ and its corresponding $p$ value are presented for the flooring comparisons for each combination of tread depth and blood type.

\begin{tabular}{ccc} 
& \multicolumn{2}{c}{ Wood v tile flooring } \\
\cline { 2 - 3 }$[\mathbf{U}(\boldsymbol{p})]$ \\
\hline Tread & Equine blood & Human blood \\
\hline \multirow{2}{*}{ No tread } & 308.5 & 29.0 \\
& $(0.274)$ & $(0.237)$ \\
Shallow & 337.5 & 32.5 \\
& $(0.589)$ & $(0.427)$ \\
Deep & 281.5 & 28.0 \\
& $(0.101)$ & $(0.244)$ \\
\hline
\end{tabular}

\subsection{Effect of footwear tread depth on quality of footwear marks}

To investigate whether the depth of the footwear tread making a mark in blood affected the quality of that mark, a Kruskal Wallis test was employed to compare the effect of footwear sole tread on the quality of footwear marks left in equine or human blood on wood or tile. The same populations of data as described above were analysed, but grouped by tread type for each flooring type. For equine blood, the test identified a significant effect of footwear tread depth on the quality of blood-based footwear marks on wood $\left(\chi^{2}=30.79, p=0.000\right)$ and on tile $\left(\chi^{2}=27.46, p=0.000\right)$. This effect was further explored by making pairwise comparisons of the different tread depths for each flooring surface using the Mann-Whitney $U$ test. It was found that, on both types of flooring, blood-based marks made by footwear with a shallow tread were of significantly higher quality those made by footwear with no tread and with a deep tread (Table 4). This trend can be clearly seen when visually comparing (b) to (a) and (c) in Fig. 4. For human blood, the Kruskal Wallis test did not identify a significant effect of footwear tread depth on the quality of blood-based footwear marks on wood $\left(\chi^{2}=1.53\right.$, $p=0.466)$ or on tile $\left(\chi^{2}=5.89, p=0.053\right)$. 
Table 4. Comparisons between footwear tread depth and mark quality for the two different types of flooring in equine blood. The Mann-Whitney $U$ statistic $(U)$ and its corresponding $p$ value are presented for each comparison of tread depth.

\begin{tabular}{ccc}
\cline { 2 - 3 } & \multicolumn{2}{c}{ Equine blood } \\
{$[\mathbf{U}(\mathbf{p})]$} \\
\hline Tread comparison & Wood & Tile \\
\hline No tread v shallow & $139.0^{\star *}$ & $160.5^{\star \star}$ \\
& $(0.000)$ & $(0.000)$ \\
No tread v deep & 296.0 & 319.5 \\
& $(0.192)$ & $(0.350)$ \\
Shallow v deep & $91.0^{* *}$ & $114.0^{* *}$ \\
* & $(0.000)$ & $(0.000)$ \\
\hline Significance at the 0.05 level; ** Significance at the 0.01 level
\end{tabular}

\subsection{Direct comparison of footwear mark quality in equine versus human blood}

Given that the experiments conducted with human blood were at fewer time points than those with equine blood, to allow a visual comparison of the results from the two blood types, the relevant data points using equine blood are reproduced in Fig. 5 (e, f, g). Such a visual comparison suggested a trend for footwear mark quality to be higher in human blood than in equine blood across the different treads and floorings; a MannWhitney $U$ test was performed to assess the significance of the difference. For the 'no tread' footwear, marks in human blood were statistically of significantly higher quality than those in equine blood on the wooden flooring, but not on the tile (Fig. 5 (a) and (d); Table 5). Marks in human blood were also statistically of higher quality than those in equine blood with the deep tread footwear on both surfaces (Fig. 5 (c) and (f); Table 5). In contrast, marks made by the shallow tread footwear were not statistically significantly different between the two types of blood on either surface (Fig. 5 (b) and (e); Table 5). 
Table 5. Comparisons between blood type and footwear mark quality for the different footwear treads on the two flooring surfaces. The Mann-Whitney $U$ statistic $(U)$ and its corresponding $p$ value are presented for the blood comparisons for each combination of tread depth and flooring surface.

\begin{tabular}{ccc}
\cline { 2 - 3 } & \multicolumn{2}{c}{ Equine v human blood } \\
& Wood & Tile \\
\hline Tread & $15.0^{*}$ & 40.2 \\
No tread & $(0.01)$ & $(1.00)$ \\
& 29.0 & 30.0 \\
Shallow & $(0.237)$ & $(0.291)$ \\
& $19.5^{\star}$ & $9.0^{* *}$ \\
Deep & $(0.04)$ & $(0.003)$ \\
\hline${ }^{*}$ Significance at the 0.05 level; ${ }^{* *}$ Significance at the 0.01 level
\end{tabular}

\subsection{Consideration of the Inge Lotz case}

The disputed bloodstain in the Inge Lotz case purportedly resulted from contact between the deep tread trainer belonging to the defendant and two drops of blood on the bathroom floor. Considering only blood marks made by the deep tread footwear on the tile surface showed that the marks of highest quality were produced in human blood, rather than in equine blood (Fig. 5(f)). The highest quality marks reached Grade 4 in human blood and Grade 2 in equine blood. Representative examples of these are shown in Fig. 6. A distinctive footwear mark and pattern of the sole can be observed in the Grade 4 mark (Fig. 6(b)). In addition, regardless of the degree to which the blood was disturbed by the footwear, the circular formation of the blood drops remained detectable across all of the trials herein (as illustrated in Fig. 6).

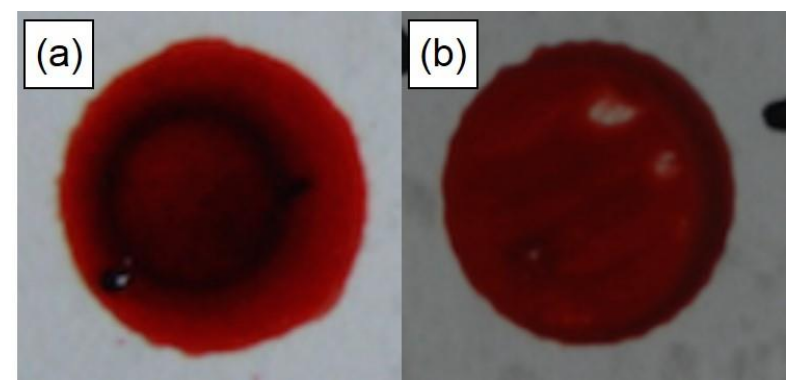

Fig. 6. Representative examples of 'deep tread' footwear marks of greatest quality on tile in equine (a) and human (b) blood. 


\section{Discussion}

This research is the first to report empirical data examining the impact of external variables on the behaviour of footwear marks left in blood, and as such, presents the beginnings of an empirical evidence base for a more accurate interpretation of such blood-based marks in forensic casework.

\subsection{Factors affecting the quality of blood-based footwear marks}

The results provide support for the hypothesis that the dryness of blood can affect resultant blood-based footwear marks, as seen in blood-based fingermark impressions [5], albeit only under certain combinations of footwear tread depth, flooring surface, and blood type (Table 2). The observed statistically significant effects were in a negative direction, that is, the quality of the footwear marks decreased with increasing time for the blood to dry. Therefore, the greatest value obtainable from blood-based footwear marks at a crime scene would most likely come from those where contact between the footwear sole and blood occurred shortly after blood deposition. A deeper understanding of how blood dryness affects footwear mark detail could improve interpretation of bloodstains, informing activity level attributions and potentially indicating temporal and spatial movements at a crime scene.

Although the blood droplets formed significantly larger circles on the tile than on the wooden flooring, the quality of the resultant footwear marks were not affected by the type of flooring surface, irrespective of the depth of footwear tread or blood type (Table 3). The lack of impact of the different flooring types may be due to the wood surface being varnished, and therefore being less porous than it would have been if left untreated. Previous research has shown that blood drops become more distorted and less circular on more porous surfaces (unvarnished wood) than on smooth nonporous surfaces (tile) [12]. The surface tension dynamics associated with porous surfaces and bloodstain distortion may have been minimised by the varnish coating, producing results akin to the non-porous tile surface, thereby leading to no significant differences between the two flooring types. The varnished wood flooring was selected in this study to represent flooring commonly found in domestic housing, however, a 
comparison of blood-based footwear marks left on both varnished and unvarnished wood could help explain the findings.

With respect to the effect of tread depth on footwear mark quality in blood, conflicting results were observed depending on the type of blood the footwear contacted. In equine blood, the shallow tread footwear produced significantly greater quality footwear marks than those made by the no tread or deep tread soles on both surfaces. However, tread depth had no effect on the quality of the resultant footwear marks in human blood, on either of the surfaces tested. These results suggest that blood type may determine the effect tread depth has on the resulting blood-based footwear marks. This raises the issue of whether equine blood is a suitable proxy for human blood when conducting research into such marks. This is further compounded by the observation in this study that footwear marks in human blood tended to be of higher quality than those in equine blood, with significant increases in quality reported for certain combinations of footwear tread and flooring surface (Table 5).

In experimental research where human blood proxies are often utilised, consideration of the blood type is required to apply the research to human bloodstains identified at a crime scene. When equine blood has been used as a human proxy (for example [6]), the equine blood is defibrinated, as it was in this study. Such removal of the fibrin protein from equine blood inhibits its ability to coagulate [13], enabling its use for experimentation after a substantial post-drawing period. However, this altering of the blood structure may affect its properties when making direct comparisons to EDTAtreated human blood, which does not have significant alterations to its structure and is more representative of untreated human blood for a limited period after being drawn [8]. Given that the EDTA-treated human blood used in this study was during this 5hour window, it may be possible to generalise the results from the current research to blood typically found at a crime scene. These results challenge previous findings that support the use of equine blood as a human proxy [7] and clearly demonstrate the need for an empirical-based systematic analysis of the sufficiency of equine blood to represent human blood found at a crime scene. 
However, in addition to differences in blood structure from the use of different anticoagulants, differences in the results obtained from the two blood types may also be due to differences in temperature of the blood. In accordance with the recommended storage guidelines for the two types of blood, the human blood was stored at room temperature $\left(\sim 24^{\circ} \mathrm{C}\right)$, whereas the equine blood was stored at $4-8^{\circ} \mathrm{C}$. Blood at room temperature is clearly a closer approximation to blood at body temperature $\left(37^{\circ} \mathrm{C}\right)$, possibly exaggerating the observed differences between human and equine blood. Therefore, additional research is required to examine whether equine blood constitutes a more effective proxy for empirical investigations when utilised at a temperature more representative of natural body temperature, if it is safe to use the blood at such high temperatures.

\subsection{Potential implications for the Inge Lotz case}

The deep tread footwear and tile selected for experimentation were representative of the footwear of the defendant and the bathroom flooring in the Inge Lotz case, making the corresponding results from this study particularly pertinent. Across all of the research trials, the marks of greatest quality were those produced by the deep tread footwear in human blood on tile (Fig.5(f)), and even these retained the circular formation of the blood drop (Fig. 6(b)). These results imply that, if the crime scene bloodstain was made by a sports trainer being placed on drops of blood, then some detail of the footwear sole should have been observed in the crime scene bloodstain, along with a circular drop formation. Such details appear to be absent from the crime scene bloodstain (Fig. 1).

Although impossible to fully reproduce the precise case circumstances, be it the volume of a blood droplet, force at which the footwear was placed on the floor, temperature of the surroundings, and the length of time the footwear was in situ, the results from this experimental study go some way towards exploring whether the crime scene bloodstain could have been formed by passive contact with footwear. These results challenge the source level proposition of the prosecution, that footwear placed in two singular blood droplet sources resulted in the crime scene bloodstain. 
Furthermore, the results derived from additional experiments that utilised other possible footwear items also showed a lack of ability to reproduce a bloodstain with any similarity to that recovered from the crime scene. It is therefore clear that the production of this evidence base demonstrates that it is not possible to infer that the crime scene bloodstain was unequivocally produced by contact with footwear. Although further research is required to explore other variables involved in this specific crime event, these results provide experimental data demonstrating the difficulty in reproducing the crime scene bloodstain with footwear contact.

\section{Conclusion}

The effects of external variables, including blood type, flooring surface, footwear tread depth and blood dryness, on the appearance of footwear marks resulting from passive contact of footwear with a blood drop were examined. Whilst the flooring surface upon which the footwear marks were made had no impact on the resulting bloodstain, depth of footwear tread and dryness of the blood significantly affected the quality of the marks produced, under particular combinations of conditions. Furthermore, footwear marks formed in human blood were generally of higher quality than those in equine blood, raising the question of whether equine blood is an appropriate proxy for human blood when conducting experiments for use in the interpretation of bloodstains in forensic casework.

Whilst only considering a limited number of variables, these data provide an initial empirical foundation regarding the impact of external factors on the appearance of resulting blood-based footwear marks. The results highlight the need for consideration of external factors and their impact on bloodstain appearance during the interpretation of such marks at a crime scene. When applied to a specific casework scenario, these results also demonstrate the importance of such experiments in assisting the interpretation of disputed evidence by narrowing the range of possible explanations for the evidence. Further research is required to explore the impact of additional variables which may be present at a crime scene that may alter the appearance of a blood-based footwear mark to improve the assignment of source and activity level attributions during crime reconstruction. 


\section{Acknowledgements}

The authors wish to acknowledge Oliver Merritt for assistance with experimental apparatus construction. We also wish to thank West Kent College, Tonbridge, and $\mathrm{Dr}$ Barbara Daniel and Dr Denise Syndercombe-Court (King's College London) for access to laboratory facilities for the experimental work to take place.

\section{References}

[1] Champod C. DNA transfer: Informed judgment or mere guesswork? Frontiers in Genetics. 2013;4.

[2] Morgan RM, Bull PA. The philosophy, nature and practice of forensic sediment analysis. Progress in Physical Geography. 2007;31:43-58.

[3] R v T. Court of Appeal of England and Wales (Criminal Division); EWCA Crim 2439; 2010. [4] Skerrett J, Neumann C, Mateos-Garcia I. A Bayesian approach for interpreting shoemark evidence in forensic casework: Accounting for wear features. Forensic Science International. 2011;210:26-30.

[5] Langenburg G. Deposition of bloody friction ridge impressions. Journal of Forensic Identification. 2008;58:355-89.

[6] Brownson DAC, Banks CE. Crime scene investigation: The effect of drug contaminated bloodstains on bloodstain pattern analysis. Analytical Methods. 2010;2:1885-9.

[7] Li B, Beveridge P, O'Hare WT, Islam M. The estimation of the age of a blood stain using reflectance spectroscopy with a microspectrophotometer, spectral pre-processing and linear discriminant analysis. Forensic Science International. 2011;212:198-204.

[8] Goossens W, Van Duppen V, Verwilghen RL. K2- or K3-EDTA: the anticoagulant of choice in routine haematology? Clinical \& Laboratory Haematology. 1991;13:291-5.

[9] Kennedy JB, Maehara KT, Baker AM. Cell and platelet stability in disodium and tripotassium EDTA. The American journal of medical technology. 1981;47:89-93.

[10] Ramsthaler F, Schmidt P, Bux R, Potente S, Kaiser C, Kettner M. Drying properties of bloodstains on common indoor surfaces. Int J Legal Med. 2012;126:739-46.

[11] Farrugia KJ, NicDaéid N, Savage KA, Bandey H. Chemical enhancement of footwear impressions in blood deposited on fabric - Evaluating the use of alginate casting materials followed by chemical enhancement. Science \& Justice. 2010;50:200-4.

[12] Peschel O, Kunz SN, Rothschild MA, Mützel E. Blood stain pattern analysis. Forensic Sci Med Pathol. 2011;7:257-70. 
[13] Olas B, Kontek B. The possible role of hydrogen sulfide as a modulator of hemostatic parameters of plasma. Chemico-Biological Interactions. 2014;220:20-4. 